\title{
Selected components of geological structures and numerical modelling of slope stability
}

https://doi.org/10.1515/geo-2019-0017

Received Oct 16, 2018; accepted Apr 03, 2019

\begin{abstract}
This paper presents the impact of selected essential aspects of geological structure on the state of slope stability as assessed by changes in the safety factor $(S F)$. The engineering geological slope features that were analysed include: (i) changes in soil cohesion and internal friction angle, (ii) presence of a weak soil layer and its span, (iii) structural discontinuity (i.e. fault), (iv) soil permeability properties and water conditions (i.e. groundwater level, long and heavy rainfall). A certain scheme of slope stability calculations has been proposed for a case involving complex geological conditions. The numerical modelling of a hypothetic slope was performed using the shear strength reduction method based on the finite element method.
\end{abstract}

Keywords: slope equilibrium state, strength parameters, geological structure, heavy rains, finite element method

\section{Introduction}

Stability of slopes is a topical and substantial issue, affecting areas where there are natural slopes as well as manmade slopes in urban areas, e.g. railway and road embankments, deep excavations or dams [1-3]. In these all cases, there are a large number of factors influencing the final safety factor value. Furthermore, numerical evaluation of the slope equilibrium state requires accurate representation in a computational model of soil and water conditions, which are determined by the geological structure. This is particularly important in areas which have been tectonically active or subject to intensive geodynamic processes in their geological history [e.g. 4-7]. This is due to the po-

\footnotetext{
^Corresponding Author: Eukasz D. Kaczmarek: Warsaw University of Technology, Faculty of Building Services, Hydro and Environmental Engineering; University of Warsaw, Faculty of Geology; Email: lukasz.kaczmarek@pw.edu.pl

Paweł Popielski: Warsaw University of Technology, Faculty of Building Services, Hydro and Environmental Engineering
}

tential occurrence of peculiar geological features, such as soil layers with reduced strength parameters [e.g. 8], layering associated with strength anisotropy [e.g. 9] and the presence of fault or discontinuity zones in the soil or rock mass [e.g. 10,11]. For this reason, numerical models often do not adequately replicate real geological conditions. As a consequence, the modelled equilibrium state may not accurately correspond to reality and the computational geometry of the mass movement slip surface may be incorrect.

Moreover, in numerical modelling there are various consequences deriving from the calculation method selected for slope stability analysis, as discussed in [1] and [12]. Appropriate definition of the slope numerical model is also important (including: right type, sufficient number and proper size of finite elements). These aspects of modelling were discussed by the authors in an earlier publication [13].

This paper presents universal multistep significance analyses of the impact of individual specific soil and water conditions of a theoretical slope on its stability, expressed in terms of safety factor $(S F)$. An evaluation of this type should be conducted in each case where there is a complex geological structure, on the basis of a properly planned parametric analysis, taking into account different cases of selected geological features.

\section{Materials and methods}

The shear strength reduction method (so called $c-\phi$ reduction method) was used for the purpose of slope stability analysis. This method was implemented in Z_soil v16.08 software based on the finite element method (FEM), as described in detail by among others [14, 15].

The analysed slope was $25 \mathrm{~m}$ high and the slope angle $\alpha$ was $30^{\circ}$. In the reference case, the slope was made of homogeneous material with the following parameters: $\gamma=22 \mathrm{kN} / \mathrm{m}^{3}, c=10 \mathrm{kPa}, \phi=30^{\circ}$. This soil was modelled using the Mohr-Coulomb (elastic-perfectly plastic) constitutive model. In addition, two other materials were used in the analysis. The first material was an isotropic soil

əopen Access. ( 2019 t. D. Kaczmarek and P. Popielski, published by De Gruyter. 
with strength parameters reduced by one-third compared to the reference case. The second material was transversally isotropic (i.e. multilaminate) in order to simulate anisotropic material behaviour. In this case, a matrix of material parameters (as in the previous case) and weakness planes strength parameters (reduced by one-third) were defined. The weakness planes dips were consistent and equal to the slope inclination. In the numerical calculations non-associated flow law was used for elasticplastic constitutive models.

Figure 1 shows the scheme of subsequent stages of the numerical analysis performed for selected components of soil and water conditions. The presented workflow is dedicated for near-surface landslides cases (related to e.g. surface soils or rock debris), opposite to very deep and complex models driven by regional geotectonic regimes.

Study of the real case according to the proposed scheme can show the scale, complexity and scope of the problem which is analysed. For real conditions, some of the factors analysed may be of little importance, while others may be taken into account in various ways. Therefore, the proposed scheme contains criteria that can be used to determine whether or not a given factor should be taken into account.

It should also be emphasised that the data needed to carry out the proposed analyses are not deterministic but they vary in relation to regional geological engineering conditions. Similarly, all analysed structural factors (e.g. thickness and location of the "weak layer", size and orientation of discontinuities, strength parameters of the soil/rock mass and contact interface, etc.) for some regions will be random to some extent. This randomness range as well as geological features recognitions defines the limits of parameter values for the sensitivity analysis.

In stage one, the impact of variation in strength parameters on $S F$ were analysed. The values of these parameters are characterized by limited certainty, which may be attributed to soil variability as well as errors in the underlying tests. First, cohesion was incrementally changed at a constant value of the friction angle of soil. After each change of cohesion, the $S F$ value was recalculated. Next, in a similar manner, the angle of friction was incrementally reduced at a constant value of cohesion. Based on the relations $S F(c)$ and $S F(\phi)$, a triaxial graph of $S F$ as a function of cohesion and internal friction angle of soil was developed. These correlations were established as a surface, which was subsequently approximated by a plane in order to determine an empirical formula for the safety factor.

In stage two, a multi-case analysis was conducted regarding the impact of the presence of a weak soil layer at different depths below terrain level. This analysis made it possible to identify the worst case scenario. Based on that (i.e. the worst case in a plane strain analysis), the study was continued with a three dimensional models analysis, so as to determine the impact of the span of a layer of reduced shear strength on the slope equilibrium state. Figure 2 shows two example models (which may represent e.g. tills, clayey sands highland or weathered colluvium clayey soil - on the slope) with different weak layer widths.

Sedimentation and diagenesis processes may result in rock structure anisotropy. Likewise weathering which can also affect the soil structure. Macroscopic manifestations of such anisotropy may include layering, lamination or a system of fractures (see Figure 3), translating into soil strength anisotropy. In the case of such materials, the use of isotropic soil models is undermined by potential major errors. Such models assume that soil strength is not dependent on the angle of load application. However, inter alia [16] provides an example of Tournemire shale to demonstrate the strength anisotropy effect: during triaxial shear tests, the strength of this material at uniaxial compression parallel to layering may be reduced by 30 to $50 \%$ compared to strength at uniaxial compression perpendicular to layering.

In modelling strength reduction (by one third in terms of both cohesion and internal friction angle), i.e. strength anisotropy of slope formations, two different approaches (A and B) were followed and a comparison of their outcomes was made. Approach A involved using interface elements in a numerical model, as they enable manual modification of strength parameters on the relevant surfaces defined by lines (see Figure 4A). These surfaces, which may be curvilinear, are input separately. Thanks to this approach it is possible to introduce even complete material discontinuity. In the alternative approach $\mathrm{B}$, we replicated anisotropy with a multilaminate constitutive model. The model belongs to a group of elastic-ideally plastic constitutive models, and it is dedicated to layered materials, such as shale [19]. In this model, it is assumed that there are linear weakness planes in a geomaterial, parallel to one another, along which displacement occurs (see Figure 4B). Weakness planes can be determined by systems with different angles relative to each other. These systems will be present throughout the defined material. On these weakness planes, the maximum strength is limited by the Mohr-Coulomb failure criterion. Various strength parameters can be determined for each of the weakness planes systems. Nevertheless, it is not possible to define strength parameters of individual weakness surfaces.

Another element of a geological structure that was analysed was structural discontinuity in the form of a fault at the base of the slope. Such elements are often 


\section{DETAIL GEOLOGICAL ENGINEERING MODEL}

NUMERICAL MODEL

Premises to include: low number and quality of in situ tests (e.g. CPTu) or lab strength tests as well as origin of soil samples used. Lack of archival results.

\section{Analysis of model sensitivity to variation in strength parametres}

A. Change of $c$ at a constant value of $\phi$

B. Change of $\phi$ at a constant value of $c$

Verification tests: additional CPTu tests in various locations, triaxial shearing tests, etc.

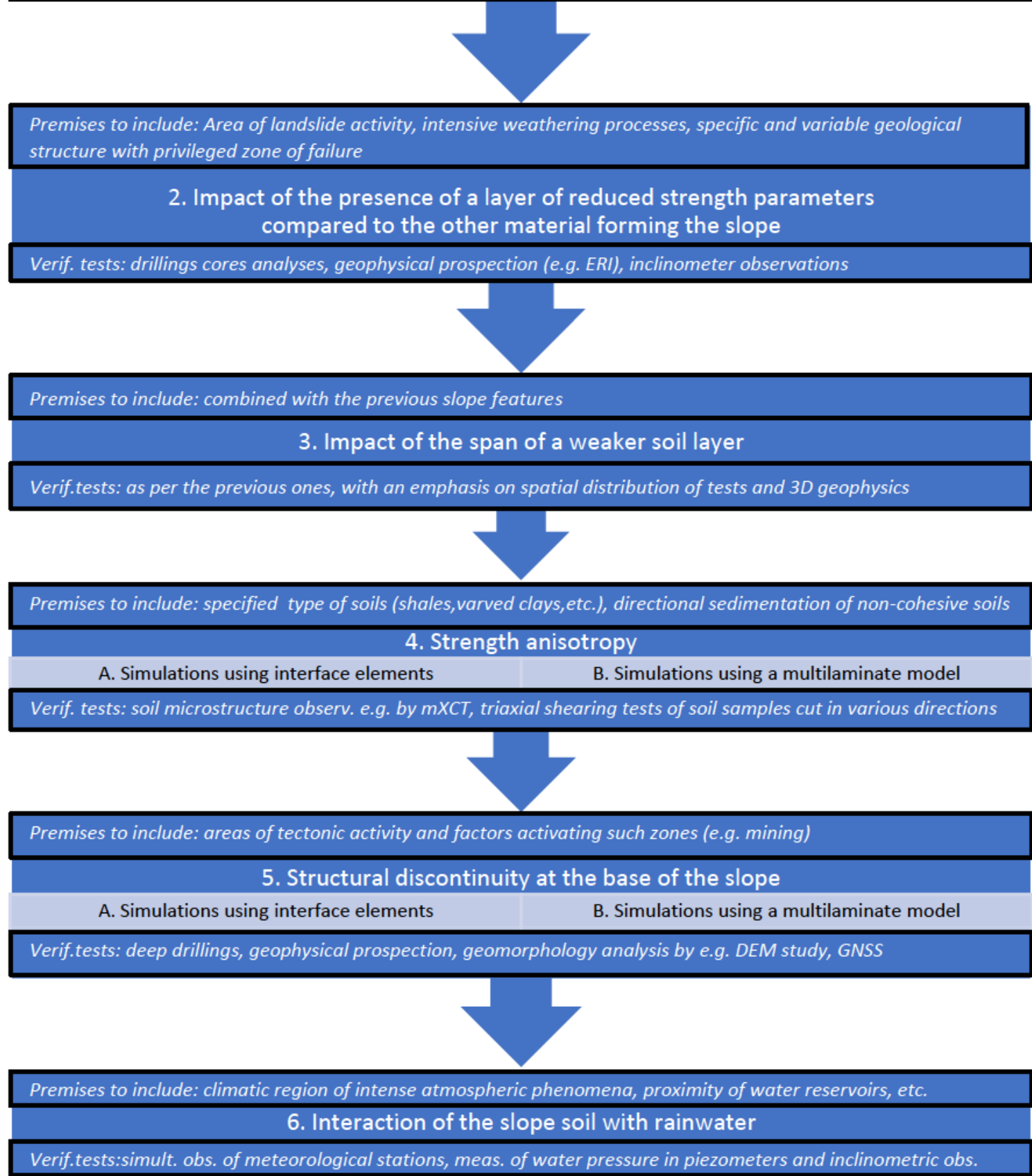

Figure 1: Flowchart of the factor-by-factor numerical analysis approach 

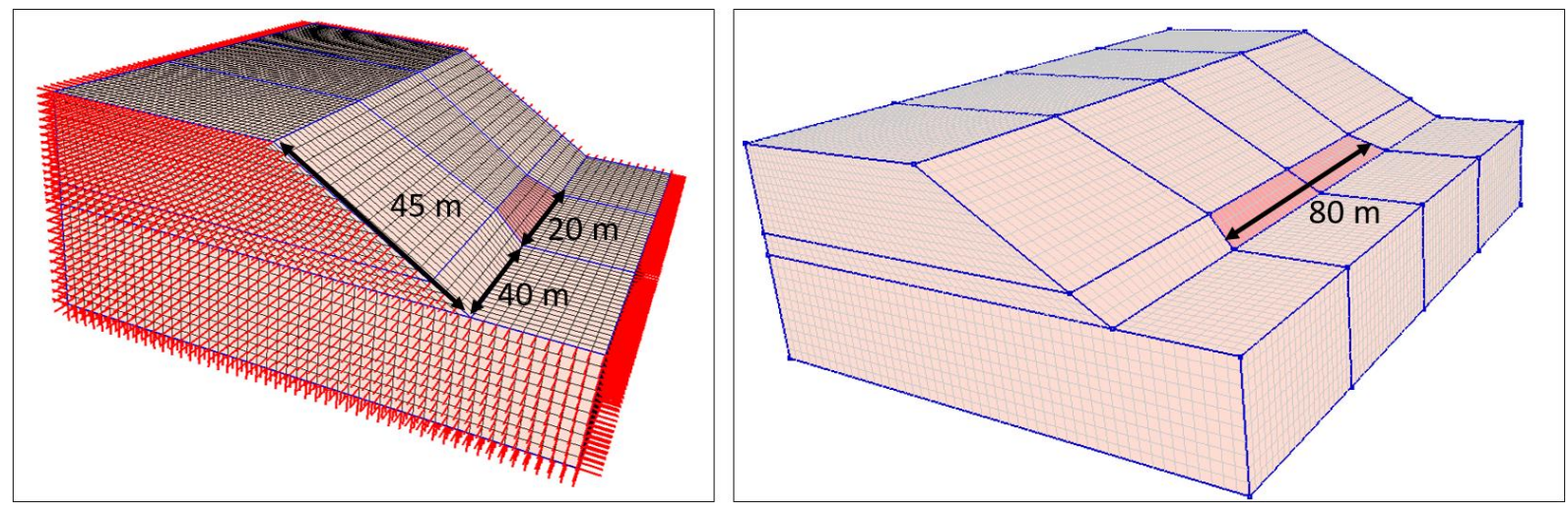

Figure 2: Exemplary models of a slope with an additional layer of reduced strength and different widths
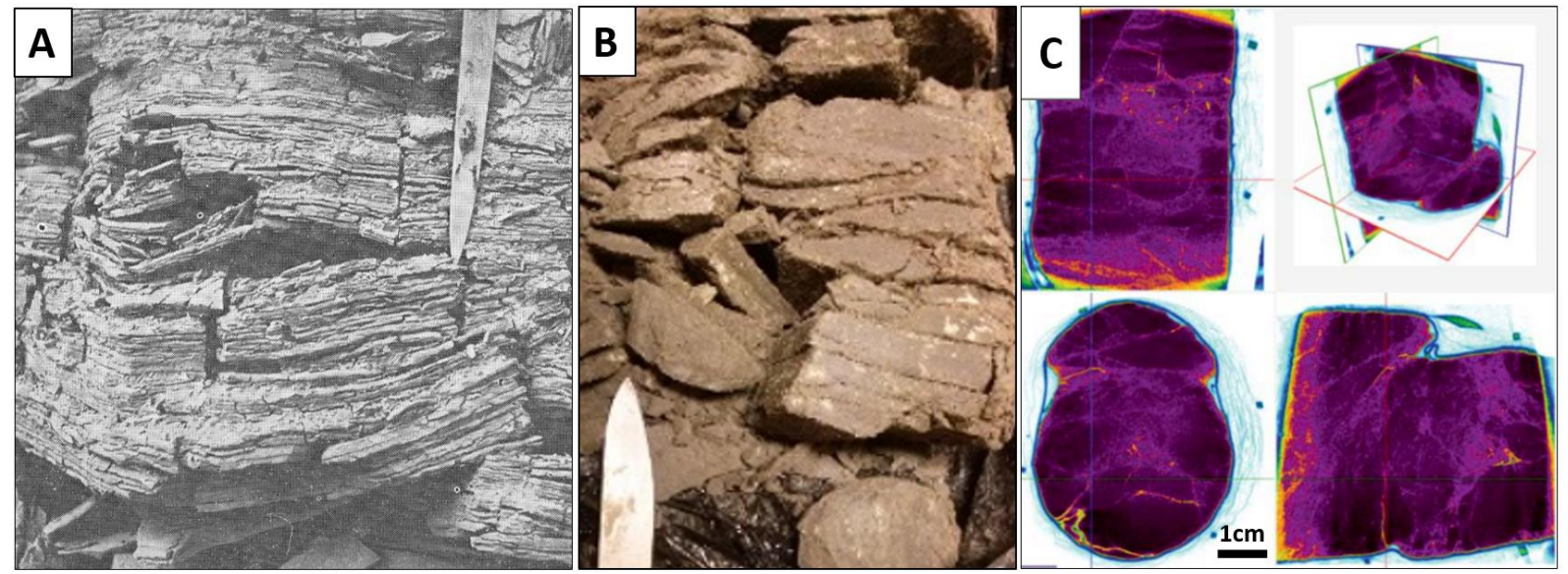

Figure 3: Structural anisotropy examples of weathered colluvium from southern Poland: (A) Miocene Krakowiec clays [17]; (B) Clay shales in the Chodenice layers; (C) Microtomographic cross-sections of a clay-shale sample after a triaxial shear test [18].
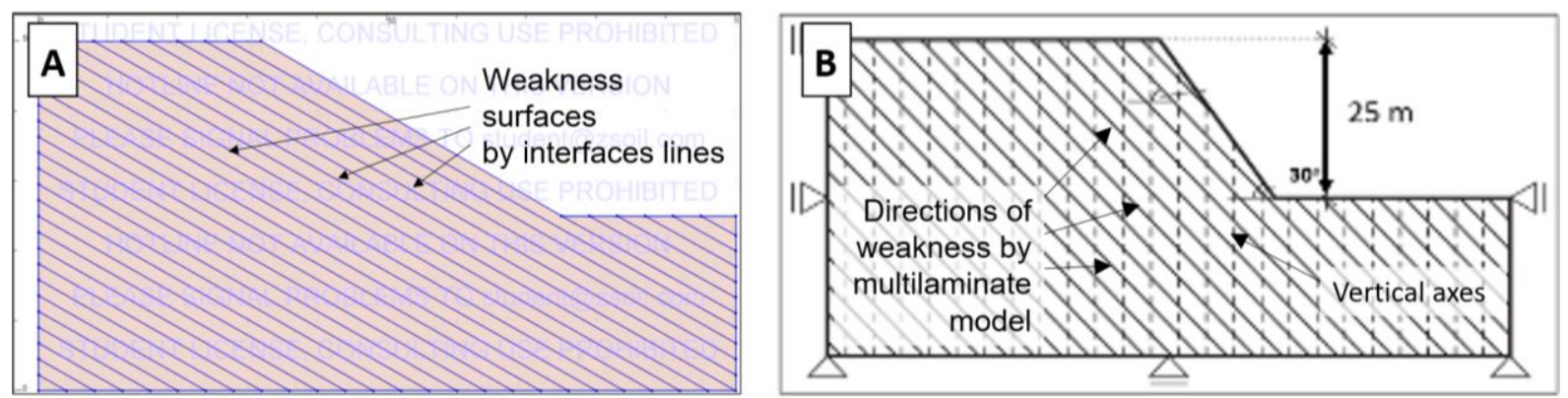

Figure 4: Slope models accounting for strength anisotropy: (A) Approach involving interface elements; (B) Schematic representation of the multilaminate model effect

neglected in numerical model construction due to insufficient depth of geological structure investigation. In the considered cases, the location of the fault was assumed under the slope, in order to verify the interactions with nearsurface landslides (i.e. the possibility of extending the slip surface). As in the case of strength anisotropy modelling, we followed two approaches (A and B). They were similar to the ones used in earlier calculations (for shear strength reduction by one third). In this case only one interfacetype surface was used in approach A, while approach B involved a limited discontinuity zone where material was defined with a multilaminate model (with weakness planes dipping at the same angle as the fault and slope inclination; see Figure 5). The fault zone is defined as multilami- 

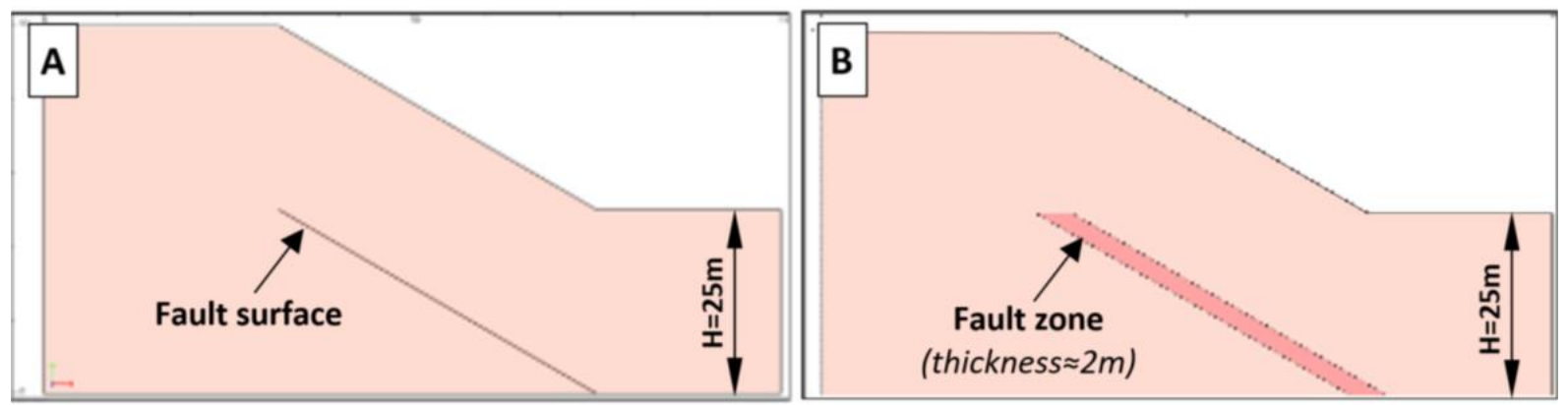

Figure 5: Models of a slope with a fault: (A) Approach based on using an interface element; (B) Approach based on using a multilaminate model
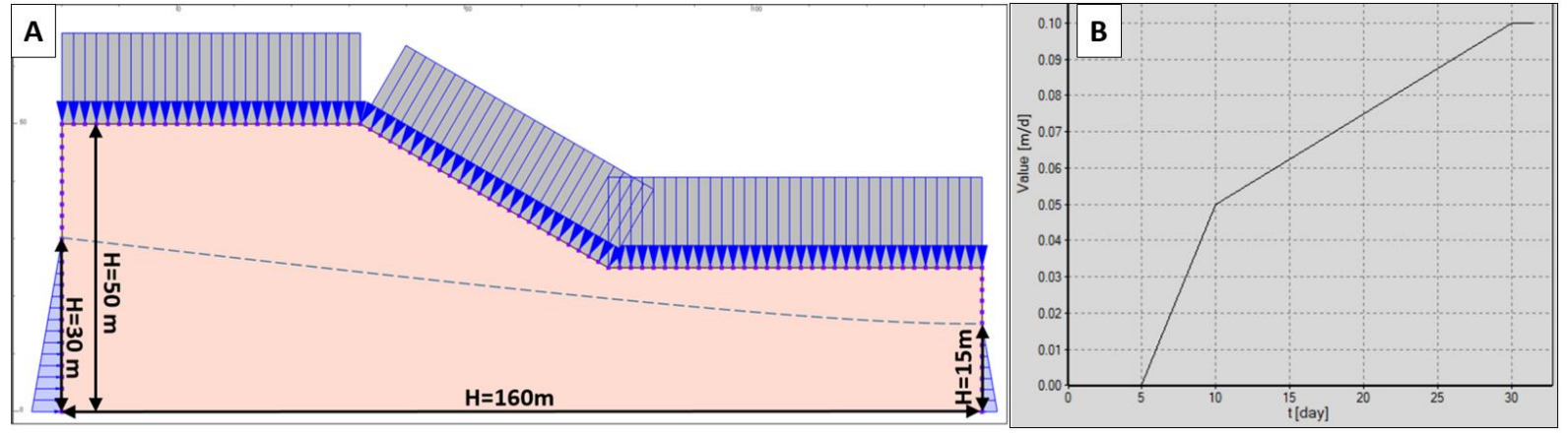

Figure 6: (A) Slope model accounting for groundwater presence and rainfall; (B) Rainfall intensity as a function of time

nate material in order to model zone filled with fractured material. An example of such use of a multilaminate model can be found in a paper by [20], who presented a case study of tunnel drilling in a faulted rock mass.

Numerical analyses of slope stability among others provide quantity evaluation of water level impact on equilibrium state [e.g. 21] as well as pore water distribution [e.g. 22]. In the presented study, the analysed scenarios focused on rainfall. This was further to analysis of 74 landslides in the Carpathian flysch belt activated in 2010, which indicated rainwater infiltration as one of the three main factors triggering landslide movements and the cause of one in five landslides [23]. Water pressure plays a major role in destabilizing slopes, as has been demonstrated multiple times in wide variety of cases [e.g. 21, 24, 25]. In order to analyse potential changes in the slope equilibrium state resulting from heavy rainfall, a model of a slope made of a homogeneous material (as described above) of the filtration coefficient $k=10^{-5} \mathrm{~m} / \mathrm{s}$ (see Figure $6 \mathrm{~A}$ ) were developed. For the purpose of the simulation, we assumed an infiltration coefficient of 0.3 , presence of groundwater as well as rainfall of growing intensity, producing an effect of water flow (expressed in $\mathrm{m}^{3} / \mathrm{d}$ ) to the slope surface (as shown in Figure 6B). In other words, rainfall has been sim- ulated as an inflow boundary condition (as suggested by [26]), where value of inflow varies in time.

\section{Results, interpretations and discussion}

In the reference case, the slope safety factor was 1.35. Figure 7A shows the geometry of the relevant slip surface. In the subsequent stage, in line with the procedure described above, the cohesion and internal friction angle were incrementally changed. Based on the results of a series of $S F$ calculations, the relation shown in Figure 7B was determined. This formula enables quick evaluation of the trend of changes and the stability safety margin for various intervals of cohesion and internal friction angle. Due to the practical application of the formula, it was decided to use the mathematical relation with friction angle values in degrees.

For slopes of simple geological structure, quasi-linear dependence of $S F$ on strength parameters enables extrapolation of results for new values of $c$ and $\phi$. However, when analysing slopes of more complex structure, the $S F$ coefficient of determination $\left(R^{2}\right)$ needs to be considered to eval- 


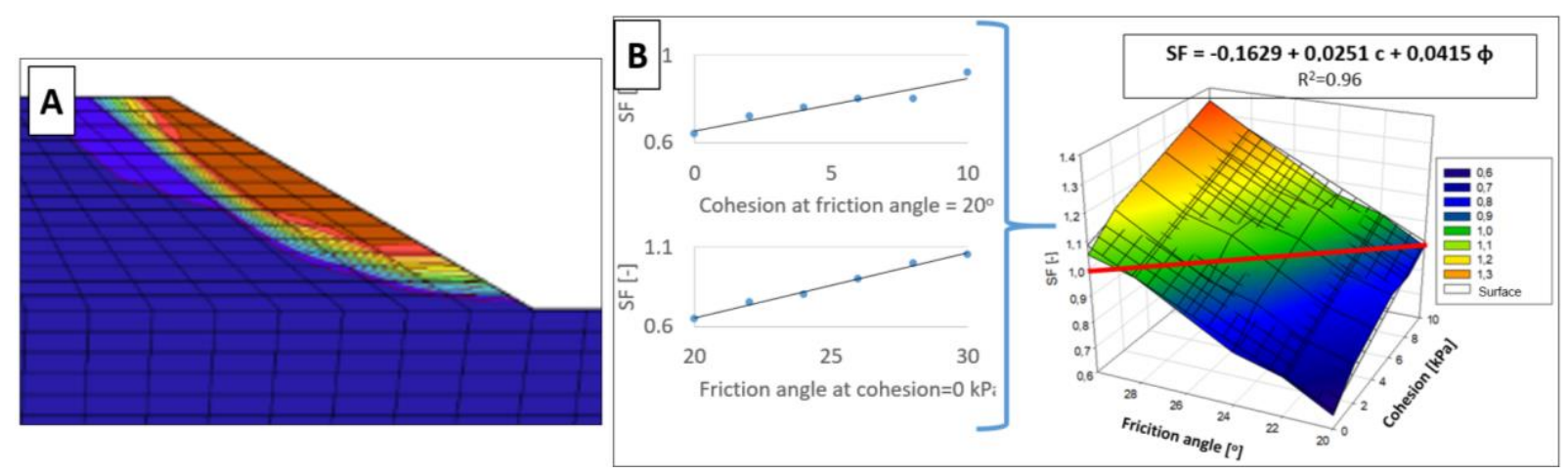

Figure 7: (A) Outcome of the safety factor calculations in stage one; (B) Determining a formula for SF depending on cohesion and internal friction angle

uate the usefulness of the outcome formula. In the analysed case, the slope equilibrium state is more sensitive to a reduction in internal friction angle, which stems from a homogenous structure and the Mohr-Coulomb criterion. A decrease in friction angle by $9^{\circ}$ (at $c=10 \mathrm{kPa)}$ results in a loss of stability, whereas a reduction of cohesion to 0 (at $\phi$ $=30^{\circ}$ ) does not result in a loss of stability (due to the angle of slope).

After determining the impact of variation in strength parameters of the material forming the entire slope, an analysis was carried out of the impact of the presence of a $5 \mathrm{~m}$ layer of reduced shear strength (one third weaker than the reference material; see Figure 8). As the depth of the weaker soil layer roof increased, the value of $S F$ decreased; in the worst case, $S F$ was reduced by approximately $30 \%$. The critical position of the new layer was at the bottom of the slope and $20 \mathrm{~m}$ below terrain level. Such an outcome is related to the presence of the longest section of the slip surface within the weaker layer. In order to analyse the impact of the span of a weaker layer on the slope, a three dimensional numerical model based on the worst case in a plane strain analysis (PSA) was created (see Figure 9).

At the further stage, the stability analysis clearly demonstrates that the impact of a reduced strength parameters layer decreases, as its width decreases, which is related to the strengthening of the lateral zones of soil. However, if a certain width is exceeded, the slope equilibrium state becomes similar to the stability of a specific case in PSA (see Figure 9) which assumes 'infinite' width of both the layer and the slope. Based on the study results, it can be concluded that three dimensional modelling provides optimisation of slope protection costs, as was also noted by [27]. Figure 9 also shows the geometry of the slip surface in a three dimensional displacement analysis, which is derived from the plain strain analysis outcome.
In the next two models of the analysed slope, strength anisotropy through interface elements and a multilaminate model, respectively, were introduced. The results of an analysis for these two approaches differ significantly (see Figure 10). In both models, there was a major decrease in $S F$; in the one with interface elements, $S F$ even fell below the critical value of 1 . Moreover, displacement fields resulting from loss of stability are also different. Interface elements enabled replication of several failure surfaces, while the multilaminate model enabled development of a translational landslide. Presumably, the reason why the results of the $S F$ calculations in the first approach are lower is that after loss of stability displacements can develop in an unlimited manner, whereas in the second approach displacements encounter soil zones which have not been plasticised. Based on such different, yet characteristic, effects, it is possible to select a model that will best correspond to the actual soil displacements observed. Most likely, for slopes made of stiff formations with high strength reduction depending on orientation (e.g. shale), the process of loss of stability will resemble the one modelled in the first approach.

The weakness planes modelling methods described above were also used to simulate a slope with a structural discontinuity surface at the base. In this case, the analysis outcome, $S F=1.2$, was the same for both approaches. However, displacement fields were still different. This time, in the first approach the displacement field is related to surficial translational slides, whereas when a multilaminate model is used in the fault zone, the entire soil mass is subject to landslide movements. Whenever areas affected by tectonic movements (such as the hills in the Carpathian flysch region) are modelled, it is frequently debated whether a surficial slide or a landslide with a deeply located displacement surface/zone occurs within a slope. The selection of the right approach to the modelling of particular 


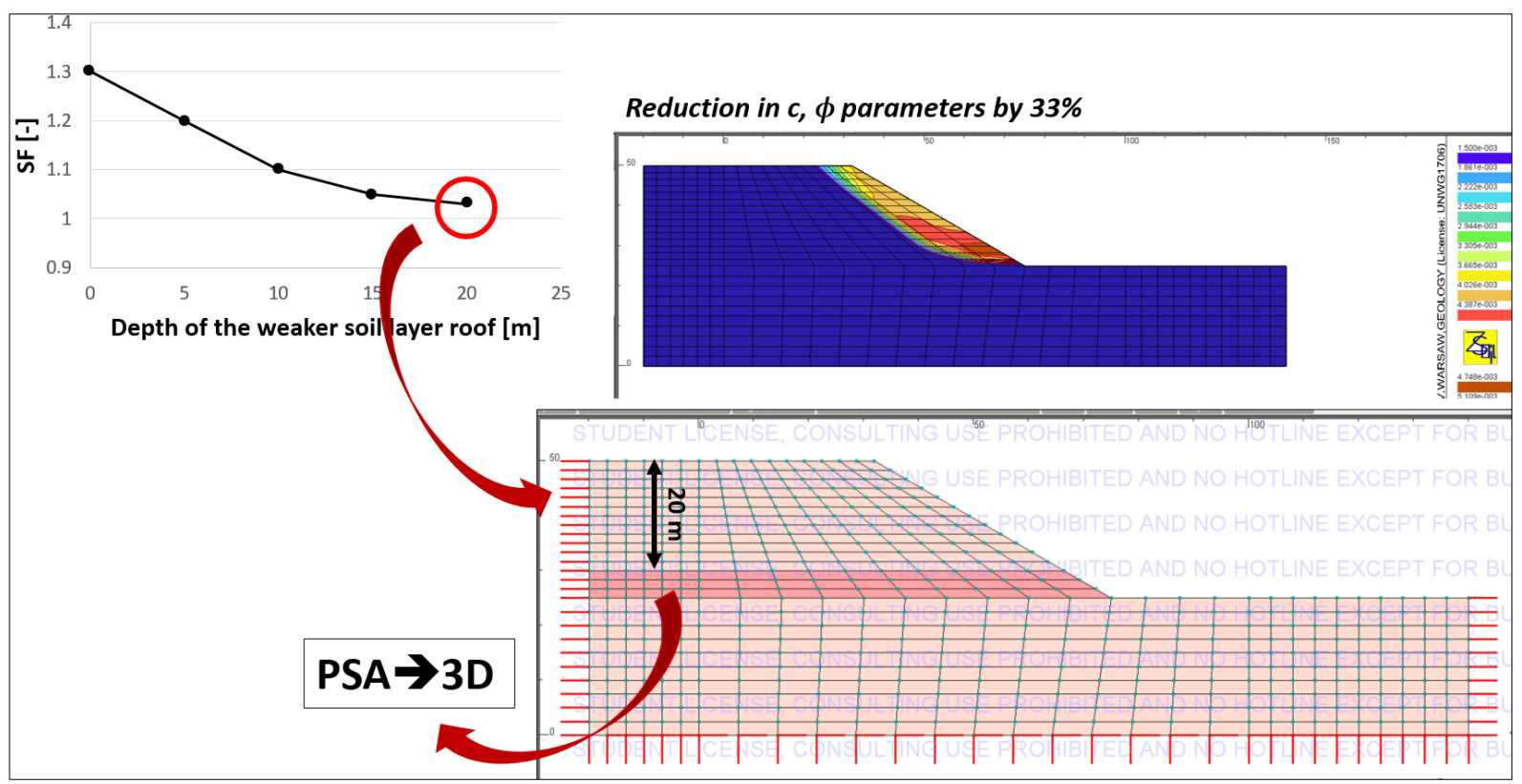

Figure 8: Outcome of a multi-case analysis of stability of a slope with a reduced shear strength layer

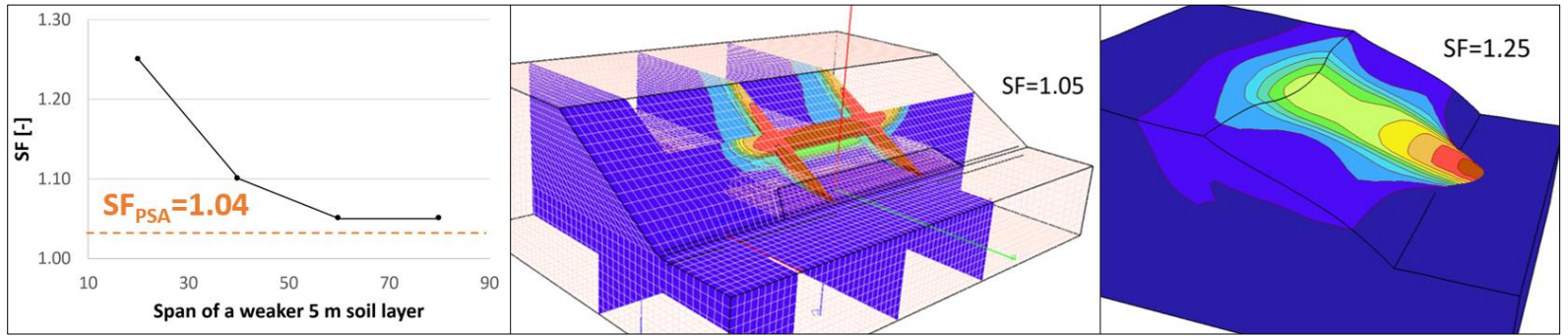

Figure 9: Results of three dimensional theoretical slope stability modelling

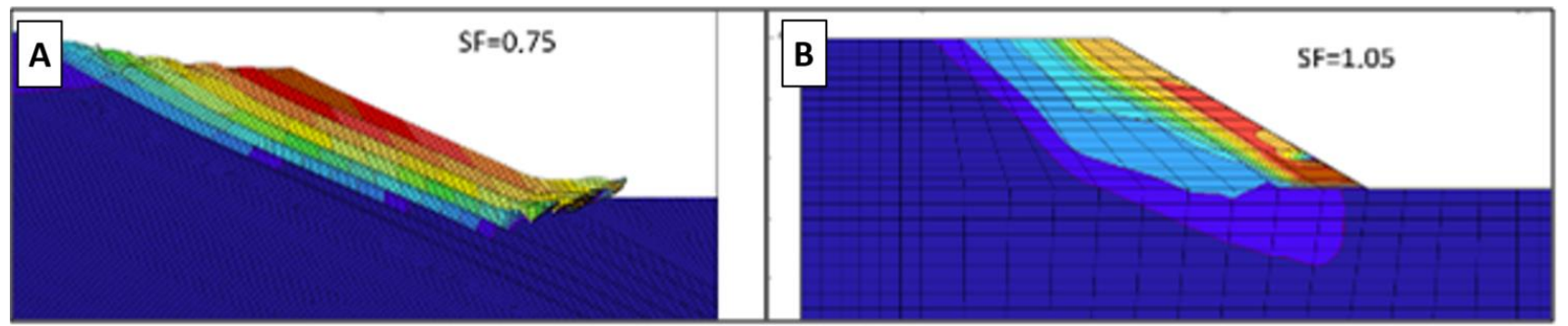

Figure 10: Two models of a slope made of a material of orientation-dependent strength reduction replicated by: (A) Model with interface elements; (B) Multilaminate material model

slopes may be based on deep investigation of their geological structure and the results of inclinometer measurements.

The geological structure of numerous slopes, together with their geometry and groundwater level, does not present a risk of activation of landslide processes. However, a factor which can drastically change the equilibrium state is soil/rock filtration properties combined with long and intensive rainfall. An example of this situation was modelled in the last stage of this numerical analysis. Figure 12 presents gradual changes in the degree of soil saturation of a slope as a result of continuous rainfall until the moment when the slope equilibrium state reaches the critical value $S F=1$. As a consequence, landslide movements are activated in a slope which was originally stable $(S F=1.35)$. 

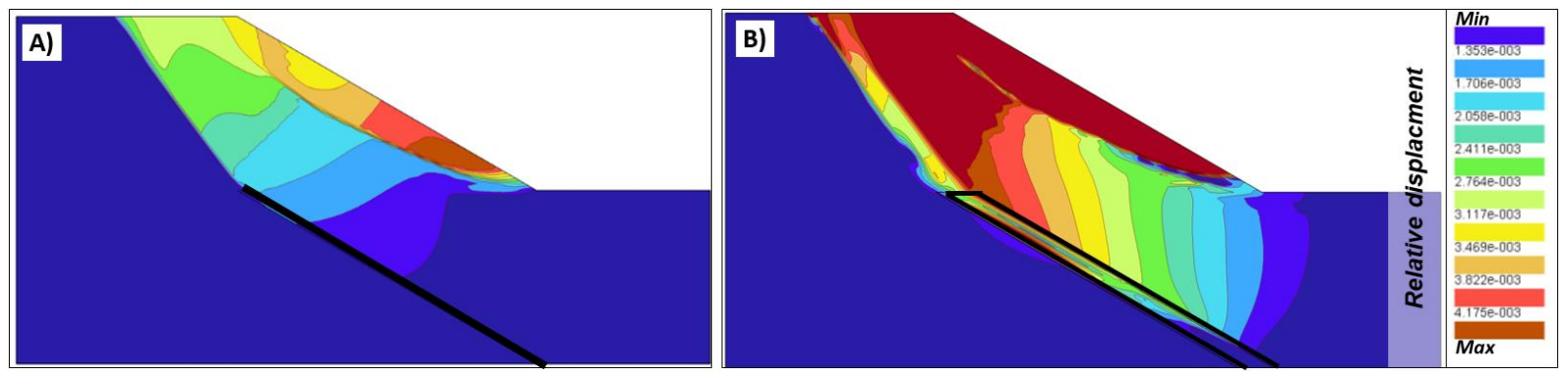

Figure 11: Two models of a slope with a structural discontinuity at the base replicated by: (A) Single interface-type element; (B) Material zone represented by a multilaminate model

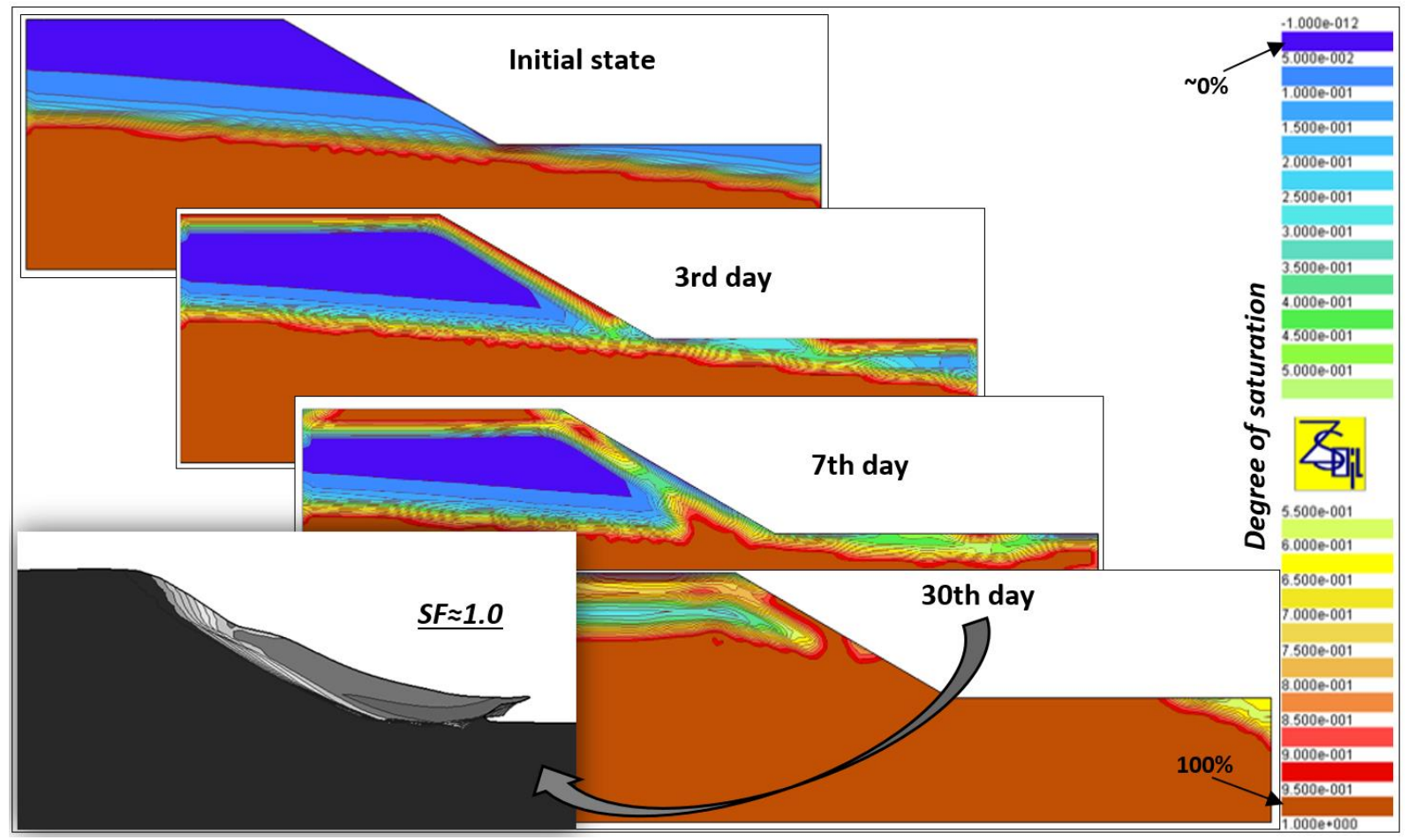

Figure 12: Model of a slope accounting for changes in saturation due to prolonged rainfall (brown colour at the slope cross-sections is correlated with full water saturation) and landslide activation moment (slope cross-section in grayscale)

The issue of convenient guidance for numerical analysis of slope stability in the presented paper is important because of the need for widespread use. New challenges like this which are related to anthropression (e.g. development of areas of man-made soils; [28, 29] or which become apparent due to new slope stability evaluation numerical methods $[30,31]$ require ongoing discussion in search of optimal solutions that can be quickly applied in the various cases along with scientific research and engineering practice [32].

At the beginning of the discussion, much attention should be paid to the calculation method. The $c-\phi$ reduction method is also implemented in software other than
Z_soil, which also use FEM or methods such as distinct element method and finite difference method (e.g. Plaxis, FLAC, UDEC, PFC, Midas, GEO5 MES). A discusion about calculation methods does not lie at the heart of this paper, but is merely indicated as one of the aspects which might affect the $S F$ results. In some particularly complex cases, calculations by two methods or even more may usefully be carried out, followed by a comparative approach to the differences. Moreover, the results of calculations using different methods can be used at various stages of geological structure recognition (e.g. initial slope stability calculations, stability calculations of individual smaller slope parts, stability calculations of the entire slope model). For 
instance, such approach can be found, in the article on numerical modeling of the deep mining in Sweden [33]. Furthermore, in some cases of slope stability analysis (e.g. slopes in simple geological conditions) analytical methods, too, provide correct $S F$ results, as has been shown in many papers, e.g. [34].

Another aspect of numerical calculations are material models. The numerical calculations in the presented study employ basic and not overly complicated constitutive material models. For some particular soils and in some sophisticated studies there is a need for more advanced models (as introduced in $[35,36])$. Nevertheless, their use requires more uncommon soil parameters.

In some untypical cases, the proposed calculation scheme will serve as a useful starting point for introducing modifications. Such a situation may occur, for example in areas that are strongly impacted by human endeavour, by e.g. highway construction, suburban development, or building of industrial sewage pipes [37]. The issue of selecting appropriate destabilizing factors lies at the heart of the basic framework for landslide risk assessment and management (described in [38]). Another example is a field characterized by highly developed vegetation, conditioning reinforcement or shallow surface landslides [3941]. Furthermore, the geotechnical reinforcment of a slope with a weak layer (in 3D FEM approach) can be considered a component of the calculation scheme [42, 43].

Through taking a factor-by-factor approach, the impact that individual components of key slope features have on stability can be quantified (observed as changes in $S F$ value). Based on these outcomes, their equivalents can be established, as was presented in [44]. In the real case, a positive development of the presented method is the additional calculations of stability, with all characteristics of the analysed slope for cumulative effect. Then, an observational method can be used to assess the reliability of the final results. Verification of this type is applied in various aspects of numerical calculations of the soil medium, such as subsidence or soil bearing capacity [45-47] which are also linked with the assessment of slope stability. The differences found in numerical calculations and field observations can be used to calibrate the numerical model [48].

Geophysical methods are one of the most frequently proposed methods for investigating the geological structure and so is proposed in the presented calculation scheme. However, one should remain prudent when using these tools, as they have their own flaws "imperfections". For instance, [49] indicate the possibility that weak and small layers are overlooked in the ERI method. In the case of slopes, such layers may be responsible for the emergence of predisposed slip surfaces, as presented in the cur- rent paper or in [27, 42]. Dahlin and Zhou [50] introduce comparison of 2D resistivity imaging electrode arrays, with their vertical and horizontal resolution. To enhance the certainty of geophysical prospecting interpretations it is useful to perform several different geophysical field tests, due to their various advantages and disadvantages [51, 52].

\section{Summary}

Numerical analyses are widely-used tools for recognition of stress and displacements fields which deepen knowledge of the mechanisms involved in landslides. Numerical models based on suitable in situ and laboratory tests calibrated with field observations, measurements of inclinometers, piezometric water level and land surveying make it possible to reliably predict changes in slope stability and in the event of an impending risk of a catastrophic landslide they provide the scientific support needed to trigger slope reinforcement works.

A multi-case numerical analysis can be used to identify the scope of outcomes along with the sensitivity of the model to variation in its different components (including erroneous assumptions made for the purpose of analysis).

The proposed scope of analysis of the slope model's usefulness:

- Mesh influence analysis (i.e. analysis of the geometry, number and size of finite elements, etc.);

- Analysis of the model's sensitivity to variation in strength parameters;

- Comparison of the outcomes of a plane strain analysis and a three dimensional analysis;

- The impact of peculiar soil features (e.g. strength anisotropy or soil layers of reduced shear strength) and structural discontinuities (e.g. faults) on the slope equilibrium state;

- Study of changes in groundwater levels caused by extreme weather (e.g. heavy rainfall, increased levels of water reservoirs and rivers).

For real conditions, some of the analysed factors (depending from geological engineering conditions and it's recognition) may be of little importance, while others may be taken into account in various ways. Therefore, the proposed scheme (at the Figure 4) contains criteria that decide whether or not to take into account a given factor and how to model it. 


\section{References}

[1] Duncan J., Wright S., Soil strength and slope stability. John Wiley and Sons, New York, 2005

[2] Schuster R. L., Highland L. M., The Third Hans Cloos Lecture. Urban landslides: socioeconomic impacts and overview of mitigative strategies. Bull Eng GEol Environ, 2007, 66, 1-27. DOI 10.1007/s10064-006-0080-z

[3] Potts D. M., Zdravkovic L., Finite element analysis in geotechnical engineering. Thomas Telford, London, 2001

[4] Borgatti L., Corsini A., Marcato G, Ronchetti F., Zabuski L., Appraise the structural mitigation of landslide risk via numerical modelling: a case study from the northern Apennines (Italy) Georisk, 2008, 2(3), 141-160. DOI: 10.1080/17499510802200261

[5] Gawriuczenkow I., Kaczmarek Ł., Kiełbasiński, K., Kowalczyk S., Mieszkowski R., Wójcik E., Slope stability and failure hazards in the light of complex geological surveys. Scientific Review Engineering and Environmental Sciences, 2017, 26(1), 85-98 (in Polish with English summary). DOI: 10.22630/PNIKS.2017.26.1.08

[6] Jastrzębska M., Łupieżowiec M., Analysis of the causes and effects of landslides in the Carpathian flysch in the area of Milówka and evaluation of their prevention methods. Ann. Warsaw Univ. of Life Sci., 2018, 50(2), 195-211. DOI: 10.2478/sggw-2018-0016

[7] Kogut J. P., Pilecka E., Szwarkowski D., Analysis of landslide effects along a road located in the Carpathian flysch. Open Geosci., 2018, 10, 517-531. DOI: 10.1515/geo-2018-0041

[8] Mohammed M., Wan L., Wei Z., Slope stability analysis of Southern slope of Chengmenshan copper mine, China. International Journal of Mining Science and Technology, 2015, 25(2), 171-175. DOI: 10.1016/j.ijmst.2015.02.002

[9] Frankovská J., Kopecký M., Panuška J., Chalmovský J., Numerical Modelling of Slope Instability. Procedia Earth and Planetary Science, 2015, 15, 309-314. DOI: 10.1016/j.proeps.2015.08.076

[10] Bossi G., Zabuski L., Pasuto A., Marcato G., Capabilities of Continuous and Discontinuous Modelling of a Complex, Structurally Controlled Landslide. Geotech. Geol. Eng., 2016, 34(5), 16771686. DOI: 10.1007/s10706-016-0057-z

[11] Cała M., Kowalski M., Stopkowicz A., The three-dimensional (3D) numerical stability analysis oh Hyttemalmen open-pit. Arch. Min. Sci., 2014, 59(3), 609-620. DOI: 10.2478/amsc-2014-0043

[12] Griffiths D. V., Lane P. A., Slope Stability Analysis by Finite Elements. Geotechnique, 1999, 49(3), 387-403

[13] Kaczmarek Ł., Popielski P., The influence of selected aspects of numerical approach on slope stability analysis results in proximity to the Warsaw Southern Ring Road. Inżynieria Morska i Geotechnika, 2016, 37(4), 210-215 (in Polish with English summary)

[14] Griffiths D. V., Lane P. A., Slope Stability Analysis by Finite Elements. Geotechnique, 1999, 49(3), 387-403

[15] Zimmermann T., Rodriguez C., Dendrou B., Z_Soil.PC: A program for solving soil mechanics problems on a personal computer using plasticity theory. In: Proceedings of the Int. Conf. on Geomechanics, Innsbruck, 1987

[16] Pietruszczak S., Fundamentals of plasticity in geomechanics. CRC Press, Leiden, 2010

[17] Kaczyński R., Wytrzymałość i odkształcalność górnomioceńskich itów zapadliska przedkarpackiego. Bulletin of Geology, 1981, 29, 105-193 (in Polish)
[18] Dobak P., Gawriuczenkow I., Kaczmarek Ł., Kiełbasiński K., Wójcik E., Application of slope stability numerical calculation for evaluation of potential displacement zones in weathered and colluvial soils on the flysh base. Prz. Geol., 2016, 64(9), 683-693 (in Polish with English summary)

[19] Commend S., Truty A., Zimmermann Th., Numerical simulation of failure in elastoplastic layered media: theory and applications. ZSOIL. PC 070404 Report. Zace Services Ltd., Lausanne, 2014

[20] Poisel A., Poisel R., About the behaviour of shafts and tunnels in a faulted rock mass. In: Konietzky H., 45. Geomechanik Kolloquium, TUBF, Freiberg, 2016, 111-124.

[21] Vrubel J., Riha J., Discussion on the safety factors of slopes recommended for small dams. Acta Univ. Agric. Silvic. Mendelianae Brun., 2017, 65(2), 569-576. DOI: 10.11118/actaun201765020569

[22] Stanisz J., Borecka A., Pilecki Z., Kaczmarczyk R., Numerical simulation of pore pressure changes in levee under flood conditions. E3S Web of Conferences, 2017, 24, 03002, doi: 10.1051/e3sconf/20172403002

[23] Kaczmarczyk R., Tchórzewska S., Woźniak H., Description of selected landslides from southern Poland activated after intensive rainfall in 2010. Biul. Państw. Inst. Geol., 2011, 446(1), 65-73 (in Polish with English summary)

[24] Huang M., Jia C., Strength reduction FEM in stability analysis of soil slopes subjected to transient unsaturated seepage. Computers and Geotechnics, 2009, 36, 93-101. DOI: 10.1016/j.compgeo.2008.03.006

[25] Ohta H., Pipatpongsa T., Heng S., Yokota S., Takemoto M., Significance of saturated clays seams for the stability of rainfallinduced landslides. Bull Eng Geol Environ, 2010, 69, 71-87. DOI: 10.1007/s10064-009-0246-6

[26] Commend S., Kivell S., Obrzud R., Podleś K., Truty A., Zimmerman Th. Computional Geomechanics on PC. ZACE Services LTD., Lausanne, 20216

[27] Cała M., Flisiak J., Tajdus A., Slope stability analysis with FLAC in $2 \mathrm{D}$ and $3 \mathrm{D}$. In: FLAC and numerical modeling in geomechanics. Proceedings of the 4th International FLAC symposium, Madrid, 2006

[28] Giordan D., Cignetti M., Baldo M., Godone D., Relationship between man-made environment and slope stability: the case of 2014 rainfall events in the terraced landscape of the Liguria region (northwestern Italy). Geomatics, Natural Hazards and Risk, 2017, 8(2), 1833-1852. DOI: 10.1080/19475705.2017.1391129

[29] Viet T., Stability assessment of man-made slopes a case study in Yen Bai. University of Twente, Enschede, 2011.

[30] Benz Th., Nordal S., Numerical Methods in Geotechnical Engineering. CRC Press, London, 2010

[31] Meng J., Wang Y., Zhao Y., Ruan H., Liu Y., Stability analysis of earth slope using combined numerical analysis method based on DEM and LEM. Tehnički vjesnik, 2018, 25(5), 1265-1273. DOI: 10.17559/TV-20161016085231

[32] Take W. A., Bowman E. T., Yune Ch.-Y., General Report: Slope Stability in Engineering Practice. Proceedings of the $19^{\text {th }}$ ICSMGE International Conf., Seoul, 2017

[33] Vatcher J., Sjöberg J., Perman F., Representing seismicity and caving in Sweden's deep mins. Proceedings of the 47th Geomechanik-Kolloquium, Freiberg, 2018

[34] Matthews C., Farook Z., Helm P., Slope stability analysis - Limit Equilibrium or the Finite Element Method ? Ground Engineering, 2014, May, 22-28 
[35] Cudny M., Vermeer P. A., On the modelling of anisotropy and destructuration of soft clays within the multi-laminate framework. Computers and Geotechnics, 2004, 31(1), 1-22. DOI: 10.1016/j.compgeo.2003.12.001

[36] Ismael M., Konietzky H., Constitutive model for inherent anisotropic rocks: Ubiquitous joint model based on the HoekBrown failure criterion. Computers and Geotechnics, 2019, 105, 99-109. DOI: 10.1016/j.compgeo.2018.09.016

[37] Preuth Th., Glade Th., Demoulin A. Stability analysis of a humaninfluenced landslide in eastern Belgium. Geomorphology, 2010, 120, 38-47. DOI: 10.1016/j.geomorph.2009.09.013

[38] Dai F. C., Lee C. F., Ngai Y. Y., Landslide risk assessment and management: an overview. Engineering Geology, 2002, 64, 6587. DOI: 10.1016/S0013-7952(01)00093-X

[39] Elia G., Cotecchia F., Pedone G., Vaunat J., Vardon Ph. J., Pereira C, Springman S. M., Rouainia M., Van Esch J., Koda E., Josifovski J., Nocilla A., Askarinejad A., Stirling R., Helm P., Lollino P, Osinski P., Numerical modelling of slope-vegetation-atmosphere interaction: an overview. Quarterly Journal of Engineering Geology and Hydrogeology, 2017, 50(3), 249-270. DOI: 10.1144/qjegh2016079

[40] Kobayashi Y., Mori A. S., The potential role of tree diversity in reducing shallow landslide risk. Environmental Management, 2017, 59(5), 807-815. DOI: 10.1007/s00267-017-0820-9

[41] Stanisz J., Kos J., Kumorowska M., Kaczmarzyk M., The influence of root system on slope stability in the view of numerical analysis. Geology, Geophysics \& Environment, 2016, 42(1), 129-130. DOI: 10.7494/geol.2016.42.1.129

[42] Ho I., Numerical study of slope stabilizing piles in undrained clayey slopes with a weak thin layer. International Journal of Geomechanics, 2015, 15(5), 06014025-1-06014025.12. DOI: 10.1061/(ASCE)GM.1943-5622.0000445

[43] Yang J., Discussion of "Numerical Study of Slope-Stabilizing Piles in Undrained Clayey Slopes with a Weak Thin Layer”, International Journal of Geomechanics, 16(4), 07015001. DOI: 10.1061/(ASCE)GM.1943-5622.0000620

[44] Kaczmarek Ł., Dobak P., Stability conditions of the Vistula Valley attained by a multivariate approach - a case study from the Warsaw Southern Ring Road. Geologos, 2015, 21(4), 249-260. DOI: $10.1515 / \log 0$ s-2015-0020
[45] Breymann H., Freiseder M., Schweiger H. F., Deep excavations in soli ground, in situ measurements and numerical predictions. Proceedings of the XIV International Conference on Soil Mechanics and Foundation Engineering, Hamburg, 1997

[46] Kasprzak A., Popielski P., Smoliński B., Evaluation of the impact of the geological structure on the results of numerical analysis of anchored diaphragm wall sand trench bottom based on the measurement made during the implementation of A14 station of metro line I in Warsaw. Prz. Geol., 2016, 64, 230-237

[47] Popielski P., Siemińska-Lewandowska A. E., The scope of soil investigation and selestion of parameters, required for the preparation of numerical models of deep foundation - experiences and conclusions. Acta Scientiarum Polonorum. Seria: Architectura, 2016, 14(4), 31-42

[48] Barański M., Popielski P., Szczepański T., Wrona M., Analysis of the possibility of the numerical model verification on the basis of the measurements and investigation carried out during a structure realization. Technical Transactions Enviromental Engineering, 2007, 1-Ś (104), 3-16

[49] Kowalczyk S., Zawrzykraj P., Mieszkowski R., Application of electrical resistivity tomography in assessing complex soil condition. Geological Quarterly, 2015, 59(2). 367-372. DOI: 10.7306/gq.1172

[50] Dahlin T., Zhou B., A numerical comparison of 2D resistivity imaging with 10 electrode arrays. Geophysical Prospecting, 2004, 52(5), 379-98. DOI: 10.1111/j.1365-2478.2004.00423.x

[51] Butler D. K., Near-Surface Geophysics Investigations in Geophysics. Alion Science and Technology Corporation, U.S. Army Engineer Research and Development Center, Vicksburg, 2005

[52] Missiaen T., Slob E., Donselaar M., Comparing different shallow geophysical methods in a tidalestuary, Verdronken Land van Saeftinge, Western Scheldt, the Netherlands. Netherlands Journal of Geosciences, 2008, 87(2), 151-164. DOI: $10.1017 /$ S0016774600023192 